University for Business and Technology in Kosovo

UBT Knowledge Center

Nov 8th, 5:00 PM - 5:15 PM

\title{
Advantages and disadvantages of application of EVA (Economic Value Added) in public companies: case of Post and Telecommunication of Kosova (PTK)
}

Uragan Alija

University for Business and Technology, uragan.alija@ubt-uni.net

Follow this and additional works at: https://knowledgecenter.ubt-uni.net/conference

Part of the Business Commons

\section{Recommended Citation}

Alija, Uragan, "Advantages and disadvantages of application of EVA (Economic Value Added) in public companies: case of Post and Telecommunication of Kosova (PTK)" (2014). UBT International Conference. 51.

https://knowledgecenter.ubt-uni.net/conference/2014/all-events/51

This Event is brought to you for free and open access by the Publication and Journals at UBT Knowledge Center. It has been accepted for inclusion in UBT International Conference by an authorized administrator of UBT Knowledge Center. For more information, please contact knowledge.center@ubt-uni.net. 


\title{
Advantages and disadvantages of application of EVA (Economic Value Added) in public companies: case of Post and Telecommunication of Kosova (PTK)
}

\author{
Uragan Alija \\ University for Business and Technology \\ uragan.alija@ubt-uni.net
}

\begin{abstract}
The Competitive companies, irrelevant of being public or private, in order to remain competitive and performing well, need and must be interested towards developing and establishing adequate performance measurement and management systems. Given the revolution of economic profit that for several decades have joined the field of corporate finance, there is a need to review existing performance management systems and provide guidance in continuous use of existing systems, or provide another view of successful innovations used by other companies and explore opportunities in adopting for internal company use. This paper examines the existing performance management system in the Post and Telecommunication J.S.C., the biggest corporation in Kosovo. This paper elaborates the use of an innovative measure called EVA. It also discusses the importance of Value Based Management, EVA concept as well as the use of 6M's. Paper concludes with several ideas on the advantages and disadvantages of EVA implementation and potential adoption as part of PTK's performance management system, which due to being a publically owned company with a privatization perspective will face it difficult to comply with strict requirements of EVA implementation in regards to its performance management approach.
\end{abstract}

Keywords: PTK, EVA, Performance Management System, Kosovo

\section{Introduction}

PTK (Post and Telecommunication of Kosova) J.S.C., an organization owned by the government of Kosova has deployed its performance management system starting in 2008. Six years later, PTK's use of its performance management system has come to a difficult process as its current system is treated as a bureaucratic and a must have system, compared to a framework that would enable PTK to track and manage its performance.

PTK was founded in 1959 and has been operational for more than 55 years. These 55 years were very challenging for PTK to achieve the market presence and economic significance that PTK plays in Kosova. Furthermore, during the 1999 war, all of the PTK assets were destroyed. After the war, with the help of the international community in Kosova, PTK was able to pull its strings together and reinstate its operations as described in PTK's website.

Today, PTK within its corporate organization runs two business units which are:

- VALA (mobile operator)

- Telecom of Kosova (provision of fixed telephony, internet and internet protocol television services). It must be noted that until July $31^{\text {st }}$, Post of Kosova (letter and parcel delivery) was also part of PTK, while as of August 1, 2012 was separated into a separate public company.

The performance management framework in PTK provided the link between strategy development and financial reward for the achievement of the strategy. Performance Management System (PMS) enabled PTK to identify its key Critical Success Factors (CSF) composed of customer, people, technology, sales and distribution and market and products.

PTK's PMS is unique as it combines both achievement of objectives and fulfillment of dimensions. However, it remains perceived as a "routine only" process. In addition, due to the lack of BSC 
integration, there is a lack of proper processes and metrics put in place. Measures such as EVA, NPV, and IRR could become very relevant for PTK.

\section{Market Environment}

The Telecommunications market in Kosovo was mainly shaped by Post and Telecommunication of Kosovo (PTK) due to its former monopoly position. Prevailing services used by Kosovars are mobile and fixed telephony, internet broadband via ADSL, Internet Television over Internet Protocol (IPTV) and Cable TV and letter and parcel delivery.

Electronic Communications market in Kosovo is seeing a decline since 2012. The decline in total revenues has continued throughout 2013 and 2014. The major decrease is consisted of decline of revenues in the mobile segment. According to RAEPC reporting for year 2013, total revenues in the telecommunications markets were $\sim 200$ Million Euros. From this amount, $81 \%$ were contributed by mobile telephony. In 2014, the decrease of mobile revenues have continued, while there were a minor increase in the household internet market.

As noted in RAEPC quarterly reporting (Regulatory Authority of Electronic and Postal Communications) in 2014, market penetration in Q2 has reached 88\%, while compared to the neighboring countries there is room for a higher penetration.

According to this report, PTK Vala holds $53.3 \%$ of subscribers base in the market, while it hold around $61.6 \%$ of revenues. In regards to fixed telephony, PTK Telekomi holds $96 \%$ of market revenues. Regarding internet, household penetration has reached 57\%, while Telekomi has $\sim 20 \%$ of internet according to users.

In general, due to different external such as privatization process, cancellation of investments and internal factors such as internal organization, separation of Post and lack of sufficient market orientation, PTK has been challenged with the decline of revenues and customer numbers.

\section{Performance Issues - internal and external factors affecting PTK's performance}

Factors affecting PTK's performance can be grouped into external and internal factors. Most important external factors are composed of competitors which in the case of PTK are IPKO Telecommunications for mobile, internet and media; Kujtesa for internet and media; Z-mobile for mobile; and other insignificant operators.

From the list above, the most important is IPKO, who as the second largest operator is moving very fast in regards to their market offering and power. Other factors affecting PTK's performance can be attributed to political and economic risks. PTK, being a public company, until end of 2013 was undergoing a very unclear privatization process, which has also affected the development of PTK. In regards to internal factors affecting PTK's performance, they can be summarized into budgetary implications, management staff, labour unions, PTK's corporate culture and staff in general. In regards to budgetary implications, there is a rising dissatisfaction of employees in general with the current business developments and the urgent need for PTK to re-focus itself. PTK is still suffering from monopolistic mentality, which was present until 2007 when IPKO, the second operator was granted the permit to operate as a mobile operator. Since then, PTK has tried to focus itself around the customer, but there was little improvement in this aspect.

PTK's executive management in order to report its performance, uses different metrics such as EBITDA - earnings before interest, tax, depreciation and amortization and ARPU - average revenue per user. In regards to ARPU, both units Vala and Telecom have noted a significant decrease in ARPU, since 2004. Main reasons are steadily falling prices for mobile and telecom services.

Furthermore, there are projects financed without proper evaluation of investment opportunities. Measures such as EVA, NPV, and IRR are not sufficiently considered even though it is believed that management acknowledges the importance and benefits coming from a proper PMS in place, but 
reluctant to implement it. Seeing the declining revenue trend of PTK, it will be of imperative to evaluate the profitability of projects and concentrate on value creation (Roztocki \& Needy, 1998).

\section{Literature review on EVA and $6 \mathrm{M}$ advantages and limitations of EVA}

Hamilton in 1777 argued that economists had come to a conclusion that if a company wants to create prosperity, it has to overcome its costs of equity and debt (Biddle, Bowen, \& Wallace, 1997). Otherwise, if companies are not able to produce profit that exceeds that cost of doing business, they will not be of interest to other investors in funding operations and projects while also risking its minimum profitability. Therefore, management responsibilities rely on making the best use of shareholders wealth by investing their proceeds efficiently (Worthington \& West, 2001) and increasing their wealth. This brings us to the concept of value based management (VFM) whose main purpose is that a company should be founded on the fundamentals of value. This involves aligning consistently key value drivers to everything a company does, be it strategy, processes, management, systems (Moskalev \& Park, 2010). Successfully implementation of VBM will be supported by corporate culture which will enable decision making using value creation concepts across organizational levels.

VBM can be best interpreted as a partnership between management processes and systems with the mind-set of value creation (Koller, 1994). These two will only work if aligned together. Furthermore, management control can only be applied by using measurement of processes, operations and competencies in a company in order to assign information to people of what action should be taken and when to take those actions.

According to Dillon \& Owers (1997), top management should be very careful, fair and consistent when choosing measurement of company activities. Most of the businesses are chasing value using outdated financial performance systems (Durant, 1999). Information regarding firm activities is presented in financial statements which are then used by shareholders, creditors, management and other stakeholders in order to evaluate performance of the company.

Recently, an innovative way of performance measurement was developed by Bennet Stewart and Joel Stern of Stern, Stewart and Company who developed the idea of free cash flow and business evaluation on cash basis, translated onto the economic value added (EVA) concept (Durant, 1999). Actually, they used the works of Modigliani and Miller, who in 1961 published the "Dividend Policy, Growth and the Valuation of Shares". Since 1982, Economic Value Added ${ }^{\mathrm{TM}}$, EVA has been introduced as registered trademark of Stern \& Stewart and Co. (later referred to as Stern Stewart) to help companies in making the best use of shareholders wealth as a measure of economic profit (Stewart B. G., 1994).

\subsection{Implementing EVA}

Until now, Eva has been utilized by many companies. It started with the cover story of Fortune Magazine highlighting the application of EVA in AT\&T and according to its financial executive; it helped AT\&T in acquiring McCaw Cellular for \$12.6 billion (Tully, 1993). Other companies that have implemented EVA: The Coca- Cola, Walmart, Whole Foods Market, Best Buy, HARSCO, Diageo, Home Depot and many others (Abate et al, 2004).

Implementing EVA in a business involves a change process backed by a strong management determination (Mäkeläinen, 1998). As Makelainen (1998) puts it, it is not about adding another row to an income statement; rather, it takes a whole process of undertaking right actions from the very beginning of implementing EVA as a change process in a company. These actions include involvement of management in discussions and obtaining their commitment through seminars, workshops and training; training of all important staff who take a stake in operational impact of EVA; embracing EVA at all levels of the company, not only as part of top management tool since it would not generate the expected effect if the operations part would not be included; and incorporate EVA in the incentive performance scheme, although Makelainen (1998) argues that this is not a must, but assists the change process and later on [may] yield positive effects after the implementation, furthermore, employees are particularly interested in schemes and systems that impact their salaries. 
In the following section of this paper, an explanation of 6 Ms of Value Based Management (VBM) developed by Stern Stewart \& Co has been provided. These 6 Ms have been adapted to PTK's environment. According to the chairman of Stern Stewart \& Co, Joel M. Stern (2009), of all corporate governance available systems, 6 Ms of VBM provide the best system for corporate governance. The realization of $6 \mathrm{Ms}$ require from companies to only invest in projects that enhance value, develop processes and systems that link the performance of employees and management to the owners perspective and careful development of reward system that motivates management and employees (Stern, 2009).

\subsection{Explanation of 6M's developed by Stern Stewart, adopted for PTK use}

The following section of the paper, reviews the 6M's developed by Stern Stewart and adopts them to the potential application of EVA to the existing performance management system.

The 6M's include:

1. M1 - Measurement Performance

2. M2 - Management

3. M3 - Motivation

4. M4 - Mindset

5. M5 - Market communication

6. M6 - Managing strategic planning

\section{M1 - Measurement Performance}

First step of PTK's process in implementing EVA is the development of EVA based management system. Main adjustments to IFRS and Kosovo based accounting procedures transform financial documents from an accounting to an economic context. Regarding PTK, EVA measures have to do with capturing the economic yield of the particular unit. Stern Stewart recommend that usual adjustments that PTK needs to consider are related to the capitalization of research and development costs and other items such as cost of company reorganization costs, staff involvement in projects.

\section{M2 - Management}

Second step of EVA implementation process, should be the managements guide to improved decisionmaking in PTK. This phase, involves the creation or review of existing projects, development of applications to analyze business intelligence, decision-making process and any other management related processes.

\section{M3 - Motivation}

Third M of Stern Stewart is the key element of EVA implementation that links shareholder value with incentives provided to management. Management by implementing EVA incentive plan through improved performance actions should be awarded bonuses for achieving greater shareholder value. As Stern (2009) suggests, considering any company, most of its motivated staff will be its sales agents who are compensated using a percentage of sales generation. The idea in the motivation part is to associate employee's compensation with EVA growth. In order to avoid myopic orientation, Stern advises that companies use a "bonus banking system", meaning that only a part of bonus is paid at the actual year, whilst the rest is kept until results have been yielded compared to planning. PTK, should pursue a system alike Goldman Sachs where the company is distinguished by the competition due to its partnership mentality between the company and employees. As such, using EVA as a performance measure, board of directors and executive managers will be indebted to only undertake projects that create value.

In order to resolve the short-sighted problem of management and ensure sustainability, PTK could move from one year planning to three year planning and link plans with the performance pay. This will ensure 
that management will be responsible for kaizen (a Japanese word for continuous improvement) type of value growth.

\section{M4 - Mindset}

The biggest difficulty for PTK in embracing EVA and implementing 6M's of Stern Stewart and Co. should be the change management process of transitioning from existing corporate culture to a value creation mindset. Using its Training and Development Center expertise, PTK should be extremely careful in adopting the right communications and training strategy. EVA implementation training should be focused in training the necessary staff on related financial topics that ensure better understanding and staff buy-in. Proper communication of EVA benefits for PTK will help achieving the successful grounds for implementation and translation from theory to practice.

It is worth mentioning the success of Whole Foods Market (WFM) who has made the list of FORTUNE magazine "100 Best Companies to Work for" taking position number 18. WFM is amongst EVA companies that have embraced value-based decision making benefiting all of its stakeholders. WFM is characterized by employment creation, salary limits for its upper wage earners and an excellent insurance medical plan (Berkowitz, 2010).

\section{M5 - Market Communication}

Another very important aspect of VBM is the market communication function. According to Stern (2009), management needs to convey clear communication to all stakeholders of the sustainability goals behind EVA system. Management needs to make sure that shareholders understand that implementation of EVA does not serve only the interest of the management; henceforth assure goal congruence in achieving value maximization.

\section{M6 - Managing strategic planning}

By implementing a clear cut value based management system, will ensure that shareholders will have a better and simpler system of monitoring the growth of the company and its value as well as being able to align goals and expectations of themselves, management and employees.

In conclusion, PTK can benefit from EVA based system in its capital distribution system, compensation systems and incentives and staff business tutoring.

\section{Conclusions}

EVA as a financial metric is a measure of value and performance (Durant, 1999). Implementation of EVA enables the company to change the way the company is managed as well as forces the company to give highest priority to increasing shareholder value. According to Stern \& Stewart Co. there are many companies that have already implemented EVA as a part of company performance measurement and base their incentive plans on EVA.

Stern et al. (1995) argue that companies implementing EVA should apply it as a total management system, meaning that EVA is a part of incentive schemes, communication with all stakeholders, goal setting and budgeting (Ittner \& Larcker, 2001), a survey of KPMG conducted on 1999 on VBM, most of the interviewed companies, use EVA related measures only at small portions, while continue to rely on traditional accounting measures.

One of the major EVA limitations, except reasons presented above, is EVA's reliance on historical information, and its one year focus. When evaluating capital projects, executive management and shareholders are interested in long-term value creation, therefore, in its simplest form EVA does not consider the impact of decisions for forthcoming years (Dillon \& Owers, 1997). This may affect managers to focus only in short-term projects and cut expenditure such as research and development or marketing (Biddle, Bowen, \& Wallace, 1997) as these expenditures will yield results in the future years; therefore by cutting those expenses, a bigger EVA is achieved to the detriment of company future. 
As stated above, performance management should and cannot be considered as "routine" process only as it can risk company's performance in the future and loose of competitive sight compared to other market players who are ready to attack using PTK's weaknesses and slow paced reaction.

In the case of PTK, assuming it wants to follow the path of the above successful companies, it will have to be very careful if deciding to implement EVA, because as Stewart III (1995) puts it, there are many companies that are failing to obtain the results they have thought to be getting due to lack of know-how during EVA implementation.

Implementation of EVA in PTK would translate that managers would be compensated for continuous improvement of EVA. As such, the focus would no longer be short term, the EVA bonus plan in PTK would need to have a form of a "bonus-bank" ensuring that reward is linked to value creation, which concept currently is challenging to be implemented due to unclear PTK's status and potential round of privatization.

As Stern, Stewart III and Chew Jr. (1995) say, by instilling a culture that puts value building above everything else through increased responsibility, persuasive incentives, decentralized decision-making and an integrated management system, it meaningfully enhances the chances of winning in the times of speedy change in the business environment. As Tully says, there are three methods that a company can use in order to increase EVA, (1) "earn more profit without using more capital", (2) make the best use of capital and (3) consider investing only in projects that promise the highest return (Durant, 1999). In this regard, PTK's management and board of directors need to work together in order to devise proper systems and measures in order to make the best use of capital, evaluate and choose best opportunities and link performance with incentives. In addition, these activities need to be carefully coordinated with the Government of Kosovo due to its future plans for PTK's privatization. However, it must be noted that the market environment that PTK is operating is quite dynamic, challenging and changing, therefore needs an immediate attention in regards to future PTK wellbeing and value protection.

\section{References}

1. Abate, J. A., Grant, J. L., \& III, G. B. (2004). The Eva Style of Investing: Emphasizing the fundamentals of wealth creation. The Journal of Portfolio Management, 61-71.

2. Berkowitz, D. L. (2010, January 21). Berk Advisory. Retrieved from Berk Advisory. In search of Economic Value Added: http://blogofberk.typepad.com/value_investing_using_eva/2010/01/evacompany-whole-foods-market-put-on-fortune-magazines-100-best-companies-to-work-forlistagain.html

3. Biddle, G. C., Bowen, R. M., \& Wallace, J. S. (1997). Does EVA beat earnings? Evidence on associations with stock returns and firm values. Journal of Accounting and Economics 24, 301-336.

4. Dillon, R. D., \& Owers, J. E. (1997). EVA® as a Financial Metric: Attributes, Utilization, and Relationship to NPV. Financial Practice and Education - Spring/ Summer, 32-40.

5. Durant, M. W. (1999). Economic Value Added: The Invisible Hand at Work. In M. W. Durant, Economic Value Added: The Invisible Hand at Work. Credit Research Foundation.

6. Koller, T. (1994). What is value-based management. The McKinsey Quarterly Number 3, pp. 87-101.

7. Ittner, C. D., \& Larcker, D. F. (2001). Assessing empirical research in managerial accounting: a valuebased management perspective. Journal of Accounting and Economics 32, 349-410.

8. Mäkeläinen, E. (1998). EVANOMICS. Retrieved from PRESENTATIONS: http://www.evanomics.com/implemen/implemenindex.shtml

9. Moskalev, S., \& Park, S. C. (2010). South Korean Chaebols and Value-Based Management. Journal of Business Ethics, 49-62.

10. PTK (2014). Financial Statements and Independent Auditor's Report. Post and Telecommunications of Kosovo J.S.C FY 2013.

11. RAEPC Kosovo. (2014). Annual Report for 2013. Regulatory Authority of Electronic and Postal Communications.

12. RAEPC Kosovo. (2014). Market situation of Electronic Communication 2014 (Q2).

13. Roztocki, N., \& Needy, K. L. (1998). An Integrated Activity-Based Costing and Economic Value Added System as an Engineering Management Tool for Manufacturers. 1998 ASEM National Conference (pp. 77-84). Virginia Beach: 1998 ASEM National Conference

14. Stern, J. M. (2009). A Message from our Chairman Joel M. Stern On Corporate Governance. Stern Stewart \& Co.

15. Stern, J. M., Stweart III, I. G., \& Chew, D. H. (1995). The EVA Financial Management System. Journal of Applied Corporate Finance, Vol. 8, No. 2, 32-46. 
16. Stewart, B. G. (1994). EVA: Fact and fantasy. Journal of Applied Corporate Finance, 7, Summer, 71-84.

17. Tully, S. (1993). The real key to creating wealth. (cover story). Fortune, 128(6), 38-52. Retrieved from EBSCOhost.

18. Worthington, A. C., \& West, T. (2001). Economic Value Added: A Review of the Theoretical and Empirical Literature. Asian Review of Accounting 9 (1), 67-86. 